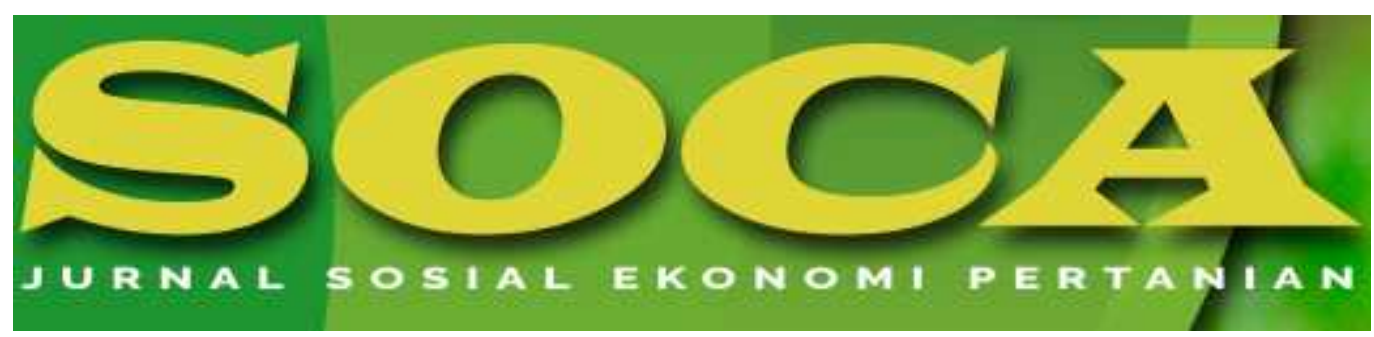

https://ojs.unud.ac.id/index.php/soca

\title{
IDENTIFIKASI KARAKTER PERMUKIMAN DI TIGA WILAYAH PEMBANGUNAN KABUPATEN BADUNG
}

\author{
Anak Agung Keswari Krisnandika, Lury Sevita Yusiana, I Made Agus Dharmadiatmika dan \\ Mar'ie Abda U'Zal
}

Prodi Arsitektur Pertamanan, Fakultas Pertanian, Universitas Udayana, Denpasar, Bali Emailkorespondensi: agung_keswari@unud.ac.id

Telepon/HP: 085741319750

Kata Kunci:
perkembangan
kawasan, sosial
ekonomi, land
cover

Kata Kunci: perkembangan kawasan, sosial cover

\begin{abstract}
Abstrak
Kabupaten Badung merupakan salah satu daerah di Provinsi Bali yang sedang berkembang dengan pesat disebabkan oleh aktivitas manusia. Perkembangan ini dapat terlihat dari karakter permukiman di daerah tersebut. Kabupaten Badung terbagi menjadi 3 wilayah pengembangan yaitu Badung Utara (Kecamatan Petang dan Abiansemal), Badung Tengah (Kecamatan Mengwi) dan Badung Selatan (Kecamatan Kuta Selatan, Kuta dan Kuta Utara). Hasil survei pada faktor biofisik seperti vegetasi, penggunaan lahan, bentuk lahan dan faktor social ekonomi menunjukkan bahwa ada beberapa karakteristik unik yang berbeda antara ketiga wilayah pembangunan di Kabupaten Badung ini. Secara umum, permukiman di Badung Utara terdiri dari perumahan yang tersusun linear di sepanjang jalan utama tetapi antar rumah cenderung dipisahkan oleh area perkebunan. Permukiman di Badung Tengah juga tersusun linier sepanjang jalan namun dengan akses kecil ke bagian belakang rumah (sawah) sementara, permukiman di sepanjang jalan utama di Badung Selatan adalah ruko diselingi oleh gang-gang kecil yang merupakan rumah-rumah penduduk.
\end{abstract}

\section{IDENTIFICATION OF SETTLEMENT CHARACTERISTICS IN THE THREE DEVELOPMENT AREAS OF BADUNG REGENCY}

\section{Keywords:}

region

development,

Abstrak
Badung Regency is a rapidly development area in Bali
Province that caused by highly human activities. This
development can be seen from the character of settlements


socio economic, land cover

\begin{abstract}
in the are. Badung regency is divided into 3 development areas namely North Badung (sub-District Petang and Abiansemal), Middle Badung (sub-District Mengwi) and South Badung (sub-District Kuta Selatan, Kuta and Kuta Utara). The survey results on biophysical factors such as vegetation, land use, landforms and human factors i.e. land boundaries, patterns, infrastructure, and regional policy show that there are some different unique characteristics between these 3 development areas in Badung Regency. In general, landscapes of settlement in the North Badung are composed of linear housing along the main road but between houses tend to be separated by plantation area. Landscapes of settlement in the Middle Badung, consist of clustered housing along the road, with small access to the back of the house (rice fields) while, houses along the main road in the South Badung are shophouses and the residents' houses are clustered linear along small alley.
\end{abstract}

How to Cite (APA 6th Style):

Krisnandika, A. A. K., Yusiana, L. S., Dharmadiatmika, I. M. A., \& U'Zal, M. A. (2020). Identifikasi Karakter Permukiman di Tiga Wilayah Pembangunan Kabupaten Badung. SOCA: Jurnal Sosial Ekonomi Pertanian, 14(1), 76-87. https://doi.org/https://doi.org/10.24843/SOCA.2020.v14.i01.p07

\section{PENDAHULUAN}

Karakter suatu kawasan (lanskap) dipengaruhi oleh beberapa faktor seperti perkembangan sosial ekonomi, budaya, populasi, kebijakan dan biofisik (Black, Morgan, dan Hessburg 2003; Antrop 2004; Xie et al. 2006; Du et al. 2014). Faktor biofisik yang dimaksud dapat berupa geologi dan tanah, landform, hidrologi, pemanfaatan dan tutupan lahan serta elemen softscape nya (vegetasi dan satwa) sementara manusia mempengaruhi karakter lanskap dari bangunan dan permukiman yang tercipta, fitur bersejarah, boundaries dan pola lahan, infrastruktur, area rekreasi serta visual yang tercipta sebagai hasil interaksi manusia dan alamnya (CLCA 2003).

Manusia menjadi faktor utama yang dapat dengan cepat menyebabkan perubahan karakter lanskap. Peningkatan jumlah manusia pada suatu lanskap sejalan dengan peningkatan/perubahan pemanfaatan lanskap dalam rangka memenuhi kebutuhan hidup manusia tersebut. Kebutuhan manusia akan tempat tinggal menyebabkan konversi lahan menjadi permukiman menempati proporsi tertinggi di pusat kota Chitaggong (Sarwar, Billa, dan Paul 2016). Tingginya kebutuhan lahan permukiman disertai perkembangan teknologi dan ekonomi menyebabkan manusia mampu memodifikasi kawasan-kawasan yang semula dianggap kurang sesuai untuk permukiman. Elmhagen et al. (2015) menjelaskan bahwa perubahan penggunaan lahan menyebabkan perubahan karakteristik pada vegetasi, tanah dan proses yang terkait, yang mempengaruhi keanekaragaman hayati dan dapat meningkatkan potensi resiko. Wu, Jenerette, dan David (2003) menemukan bahwa urbanisasi telah membuat lanskap wilayah metropolitan Phoenix secara struktural lebih terfragmentasi dan kompleks. Aspek biofisik lanskap 
seperti kemiringan lereng merupakan salah satu faktor yang dijadikan kriteria dalam pembangunan kawasan permukiman. Pembangunan permukiman diharapkan tidak dilakukan pada daerah dengan kemiringan lebih dari 25\% karena rawan terjadi bencana dan dapat menurunkan kualitas lingkungan.

Kabupaten Badung merupakan daerah yang memiliki kepadatan penduduk terbesar kedua di Bali dan diproyeksikan akan terus meningkat hingga mencapai 683.2 ribu jiwa pada 2020 (BPS 2018). Pariwisata menyebabkan perkembangan ekonomi yang pesat diiringi dengan urbanisasi yang tinggi terjadi di kabupaten ini. Wilayah Kabupaten Badung yang tersebar pada berbagai tingkat kemiringan lereng $(0->40 \%)$ menyebabkan besarnya kemungkinan terjadi konversi lahan untuk permukiman pada lahan yang memiliki kemiringan lebih dari 25\%. Untuk mendapatkan peta pola perkembangan kawasan permukiman pada lahan di berbagai tingkat kemiringan lereng, pada penelitian ini digunakan data penginderaan jauh yang kemudian diolah menggunakan sistem informasi geografis (SIG). Selain alih fungsi lahan, faktor sosial ekonomi dan geografis (kemiringan lereng, morfologi tanah dan lainnya) juga dilaporkan dapat menyebabkan adanya perbedaan karakter pada lanskap permukiman (Odeh et al. 2017; Peng dan Hsieh 2015; Putri 2013; Hudayya 2010; Marwasta dan Priyono 2007). Berdasarkan wilayah pembangunannya, Kabupaten Badung terbagi menjadi 3 yaitu Utara (Kecamatan Petang dan Abiansemal), Tengah (Kecamatan Mengwi) dan Selatan (Kecamatan Kuta Selatan, Kuta dan Kuta Utara) dengan sektor unggulan yang berbeda-beda (Pemkab Badung 2018). Perbedaan kondisi gerografis serta sosial ekonomi di masing-masing wilayah mungkin akan berdampak pada perubahan karakter permukiman di Kabupaten Badung. Oleh sebab itu, tujuan dari penelitian ini adalah untuk mendapatkan peta pola sebaran permukiman di Kabupaten Badung berdasarkan lima kelas kemiringan lereng, serta menganalisis karakter lanskap permukiman sesuai kategori kemiringan lereng.

\section{METODE PENELITIAN}

Penelitian ini dilakukan pada tahun 2018 di Kabupaten Badung. Metode analisis spasial secara pengindraan jauh dan pengolahan data SIG digunakan dalam penelitian ini. Analisis ini akan digunakan untuk mengintegrasikan data peta citra dengan data sekunder. Hasil analisis spasial kemudian diuji melalui metode survei ke lokasi yang ditentukan untuk mengambil data-data berikut (Tabel 1.)

Tabel 1. Data survei

\begin{tabular}{|c|c|c|c|c|}
\hline No. & Jenis Data & Parameter & Bentuk & Sumber \\
\hline 1. & Tapak & $\begin{array}{l}\text { Topografi, } \\
\text { landmark, } \\
\text { boundaries dan pola } \\
\text { lahan, area rekreasi } \\
\text { serta visual. }\end{array}$ & data primer & $\begin{array}{l}\text { Survei } \\
\text { dokumentasi }\end{array}$ \\
\hline 2. & $\begin{array}{l}\text { Elemen } \\
\text { buatan }\end{array}$ & $\begin{array}{l}\text { Bangunan, } \\
\text { perkerasan, fitur } \\
\text { bersejarah, } \\
\text { infrastruktur. }\end{array}$ & data primer & $\begin{array}{l}\text { Survei } \\
\text { dokumentasi }\end{array}$ \\
\hline
\end{tabular}




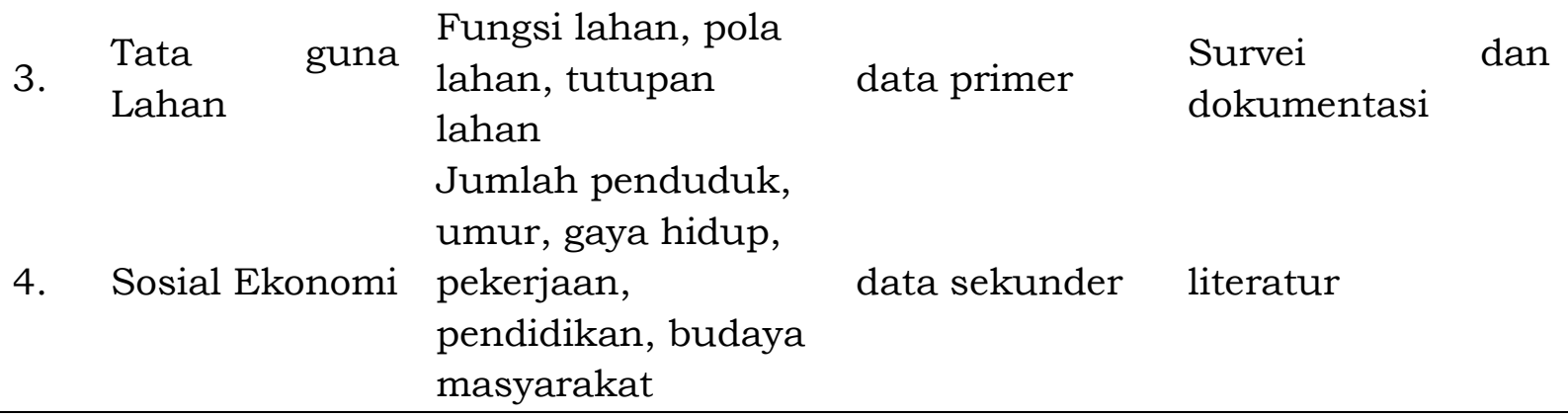

Metode deskripstif lalu digunakan untuk menggabungkan seluruh data hasil penelitian yang diperoleh untuk mendapatkan karakter lanskap permukiman di kabupaten Badung.

\section{HASIL DAN PEMBAHASAN}

\section{Gambaran Umum}

Kabupaten Badung terbagi atas 6 kecamatan yaitu Kuta Selatan, Kuta, Kuta Utara, Mengwi, Abiansemal dan Petang (Gambar 1.) dengan total luas wilayah $418.52 \mathrm{~km}^{2}$ dan kepadatan penduduk 1,5/ $\mathrm{km}^{2}$ (BPS, 2017). Kecamatan Kuta merupakan daerah dengan kepadatan penduduk per $\mathrm{km}^{2}$ tertinggi yaitu 5,87 sementara Petang memiliki kepadatan penduduk terendah yaitu 0,23/ $\mathrm{km}^{2}$. Objek wisata alam terutama pantai mendominasi di Kecamatan Kuta Selatan diikuti oleh Kuta dan Kuta Utara, sementara Kecamatan Abiansemal, Mengwi dan Petang masih didominasi oleh lahan pertanian (Tabel 2.).

Tabel 2. Pemanfaatan lahan pada masing-masing kecamatan di Kabupaten Badung

\begin{tabular}{lccc}
\hline Kecamatan & $\begin{array}{c}\text { Kepadatan } \\
\text { per } \mathrm{km}^{2}\end{array}$ & Lahan bukan pertanian (\%) & Obyek wisata \\
\hline Kuta Selatan & 1,51 & 65 & 15 \\
Kuta & 5,87 & 89 & 5 \\
Kuta Utara & 3,76 & 54 & 3 \\
Mengwi & 1,59 & 18 & 5 \\
Abiansemal & 1,32 & 14 & 5 \\
Petang & 0,23 & 12 & 5 \\
\hline
\end{tabular}

Sumber: BPS, 2017

\section{Analisis spasial}

Peta kontur Kabupaten Badung didapatkan dengan memanfaatkan peta Shuttle Radar Topography Mission (SRTM). Selanjutnya dilakukan ekstraksi masking area dan penyesuaian koordinat Peta SRTM agar sesuai dengan keadaan wilayah yang sebenarnya. Ekstraksi slope dilakukan kemudian untuk menghasilkan peta kemiringan lereng. Peta kemiringan lereng tersebut diklasifikasikan berdasarkan lima kelas kemiringan lereng yaitu datar (0-8\%), landai (8-15\%), agak curam (15$25 \%$ ), curam $(25-45 \%)$, dan sangat curam ( $\geq 45 \%)$. Peta kemiringan lereng (Gambar 2a.) kemudian ditumpangtindihkan dengan peta sebaran wilayah terbangun di Kabupaten Badung didapatkan melalui pengklasifikasian lahan dengan metode supervised classification pada Citra Landsat Kabupaten Badung, sehingga dihasilkan sebaran wilayah terbangun di berbagai tingkat kemiringan (Gambar 2b.). 


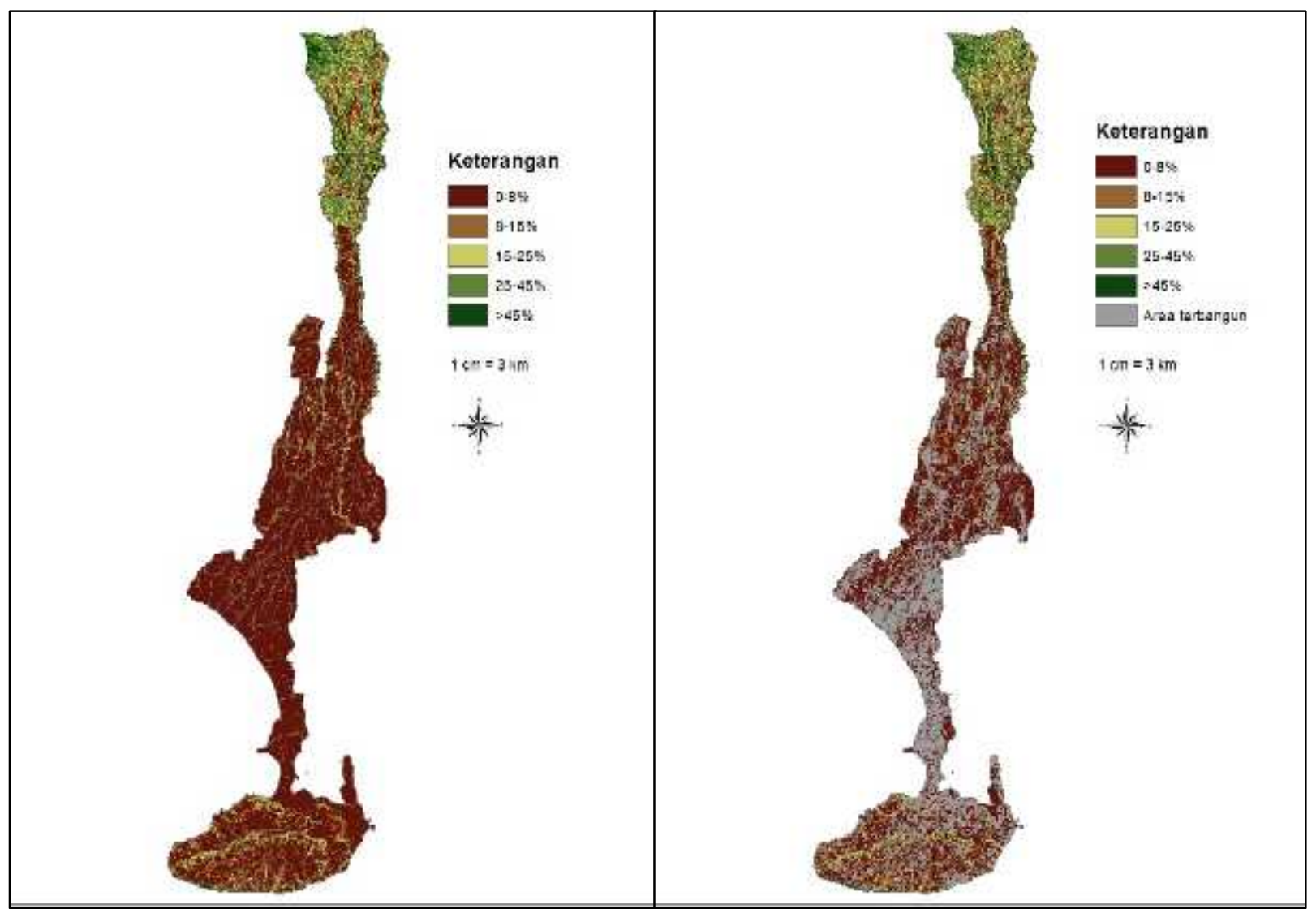

Gambar 1. Kabupaten Badung; a. sebaran kemiringan lereng; b. area terbangun di berbagai tingkat kemiringan.

Kecamatan Petang yang berada di wilayah paling utara dari kabupaten Badung memiliki wilayah dengan kemiringan di atas 45\% (sangat curam) terbanyak di kabupaten Badung. Kecamatan lainnya di Kabupaten ini cenderung didominasi oleh kawasan landai (kemiringan 0-8\%). Hasil ini juga menunjukkan hampir seluruh wilayah landai sudah didominasi oleh area terbangun terutama Kecamatan Kuta. Hal ini sesuai dengan data dari BPS (2017) yang menyatakan Kecamatan Kuta merupakan kecamatan yang memiliki kepadatan penduduk tertinggi di Kabupaten Badung.

\section{Survei}

Suvei yang dilakukan pada 19 titik di Kabupaten Badung (Gambar 2) menunjukkan secara umum terdapat tiga karakter wilayah di Kabupaten Badung berdasarkan topografinya yaitu daerah dataran (Badung Tengah), pegunungan (Badung Utara) dan perbukitan (Badung Selatan). 


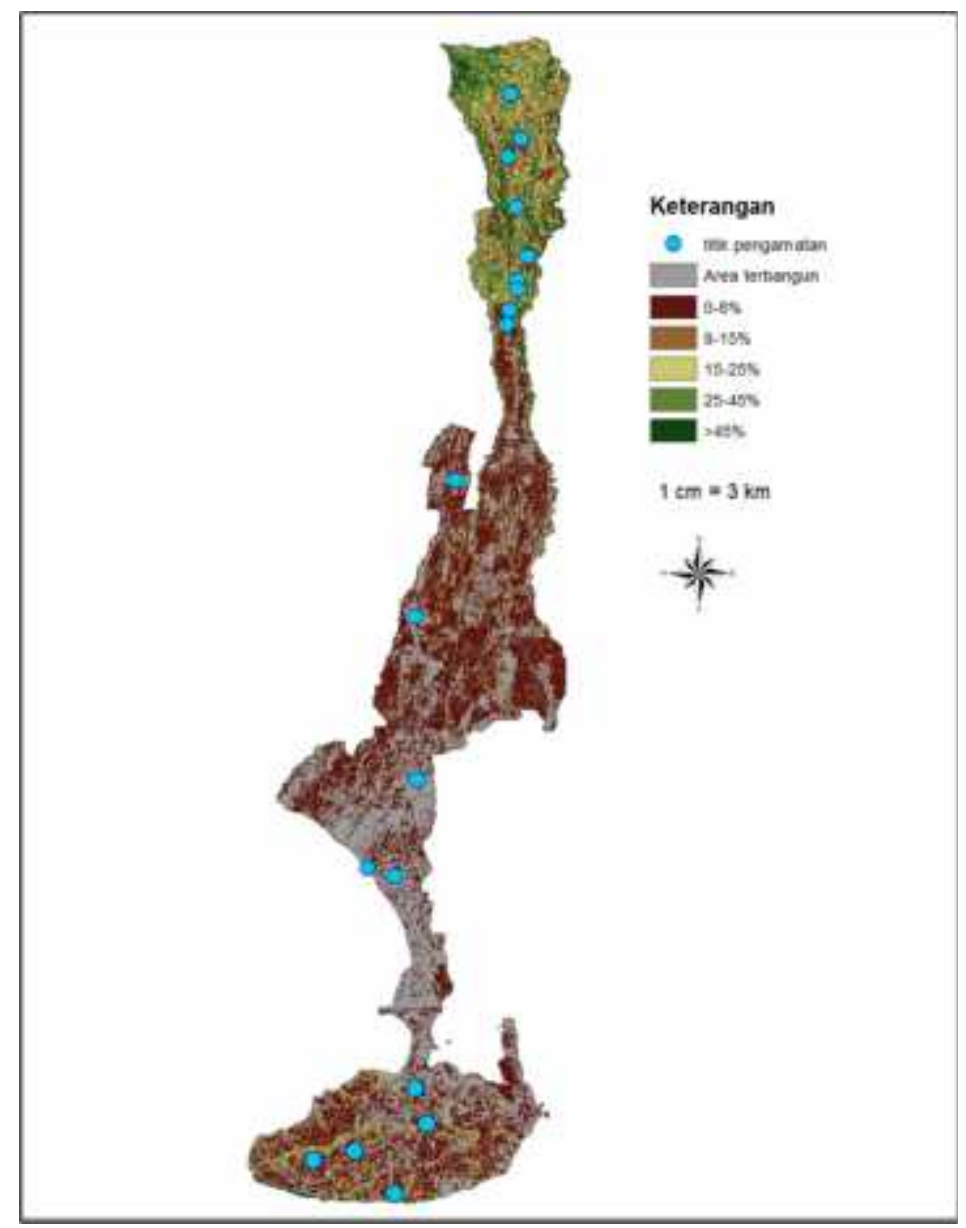

Gambar 2. Lokasi survei

Adapun karakter permukiman dari masing-masing wilayah tersebut, sebagai berikut:

Kemiringan 1 (0-8\%)

Permukiman di daerah Badung Utara memiliki kepadatan yang rendah, umumnya hanya terdiri atas satu baris perumahan yang linier mengikuti jalan utama (Gambar 3a.). Model bangunannya masih tradisional dan cenderung homogen, pekarangan sudah mulai ditata walaupun sederhana. Ladang sebagai sumber penghasilan warga berada di samping rumah (3d.). Permukiman masih dilatarbelakangi oleh pepohonan hijau, bangunan belum tinggi serta karakter pegunungan masih terasa. Permukiman di daerah Badung Tengah memiliki kepadatan yang cukup tinggi, tersusun linier mengikuti jalan disertai akses-akses jalan masuk untuk menfasilitasi permukiman pada baris-baris di dalamnya (Gambar 3b.). Model bangunannya sudah campuran antara tradisional dan semi modern, pekarangan sudah mulai ditata dengan memperhatikan fungsi estetik (Gambar 3e), bangunan belum tinggi, suasana perkotaan mulai terasa. Permukiman di daerah Badung Selatan memiliki kepadatan yang tinggi, tersusun linier mengikuti jalan disertai akses-akses jalan masuk yang sangat kecil untuk menfasilitasi permukiman pada baris-baris di dalamnya (Gambar 3c.). Terdiri atas ruko di sepanjang jalan, perumahan warga di barisan belakang dari ruko serta vila-vila 
kecil. Model bangunannya sudah modern, perkarangan yang luas dan hijau di sepanjang ruas jalan sedikit ditemukan (Gambar 3f).

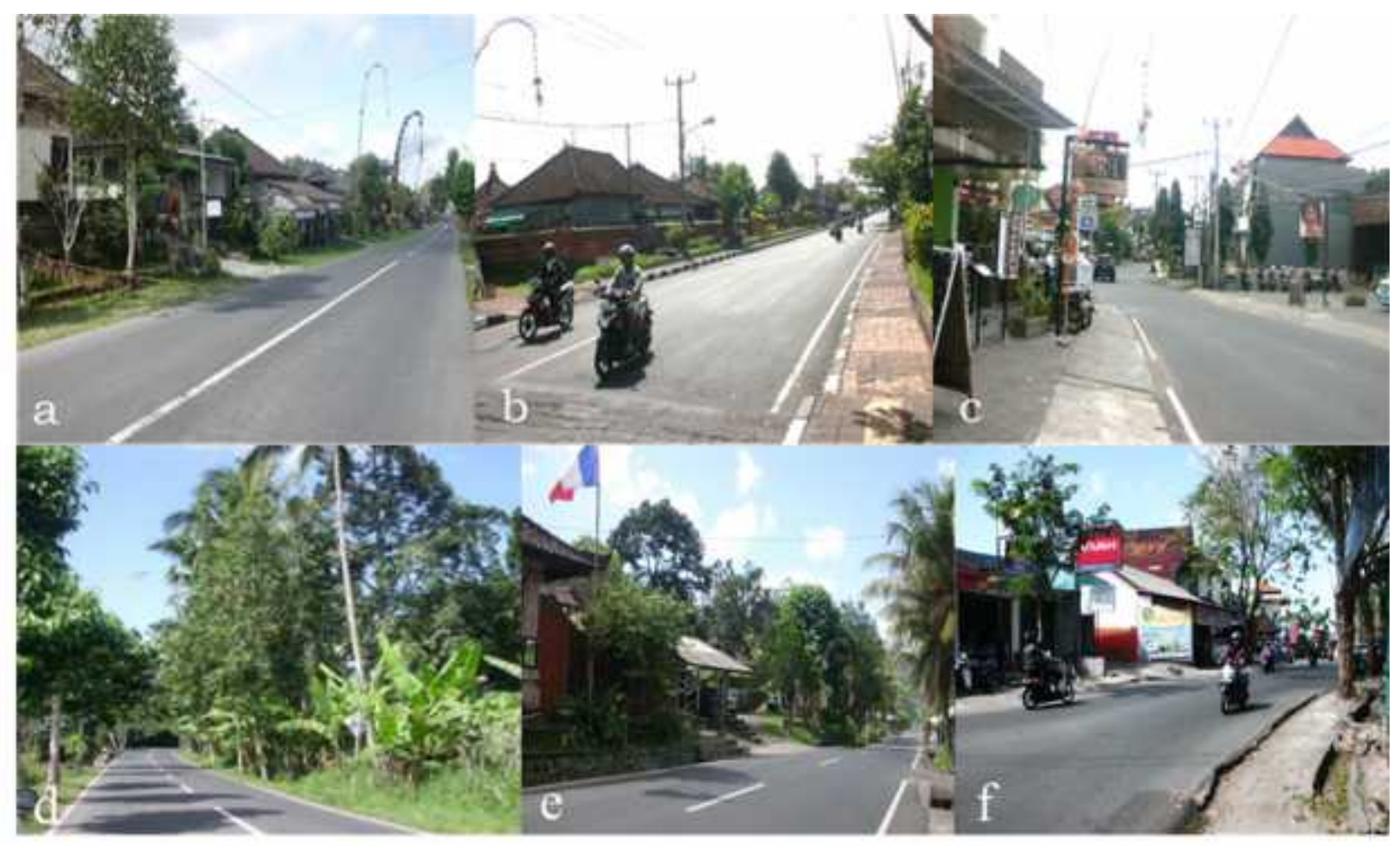

Gambar 3. Permukiman dan hijauan di sepanjang jalan Badung Utara (a,d); Tengah (b,e); Selatan (c,f).

Kemiringan 2 (8-15\%)

Kepadatan permukiman masih rendah, permukiman dibangun mengikuti kontur, umumnya hanya terdiri atas satu baris perumahan yang linier mengikuti jalan (Gambar 4a.). Model bangunannya masih tradisional dan cenderung homogen. Pekarangan sudah mulai ditata walaupun sederhana. Ladang sebagai sumber penghasilan warga berada di belakang rumah (Gambar 4e.), sudah ada ruko walaupun masih sangat jarang. Permukiman masih dilatarbelakangi oleh pepohonan hijau. Bangunan belum tinggi, karakter pegunungan terasa. Badung tengah dan Selatan pada kemiringan ini memiliki permukiman yang dibangun secara terencana, pekarangan sudah tertata rapi, model bangunannya modern (Gambar 4b, 4c, 4d, 4f). Rumah tersusun secara berkelompok. Mata pencaharian penduduk sudah bervariasi. Social ekonomi menentukan bentuk rumah dan luasnya. Akses jalan sudah direncanakan. 


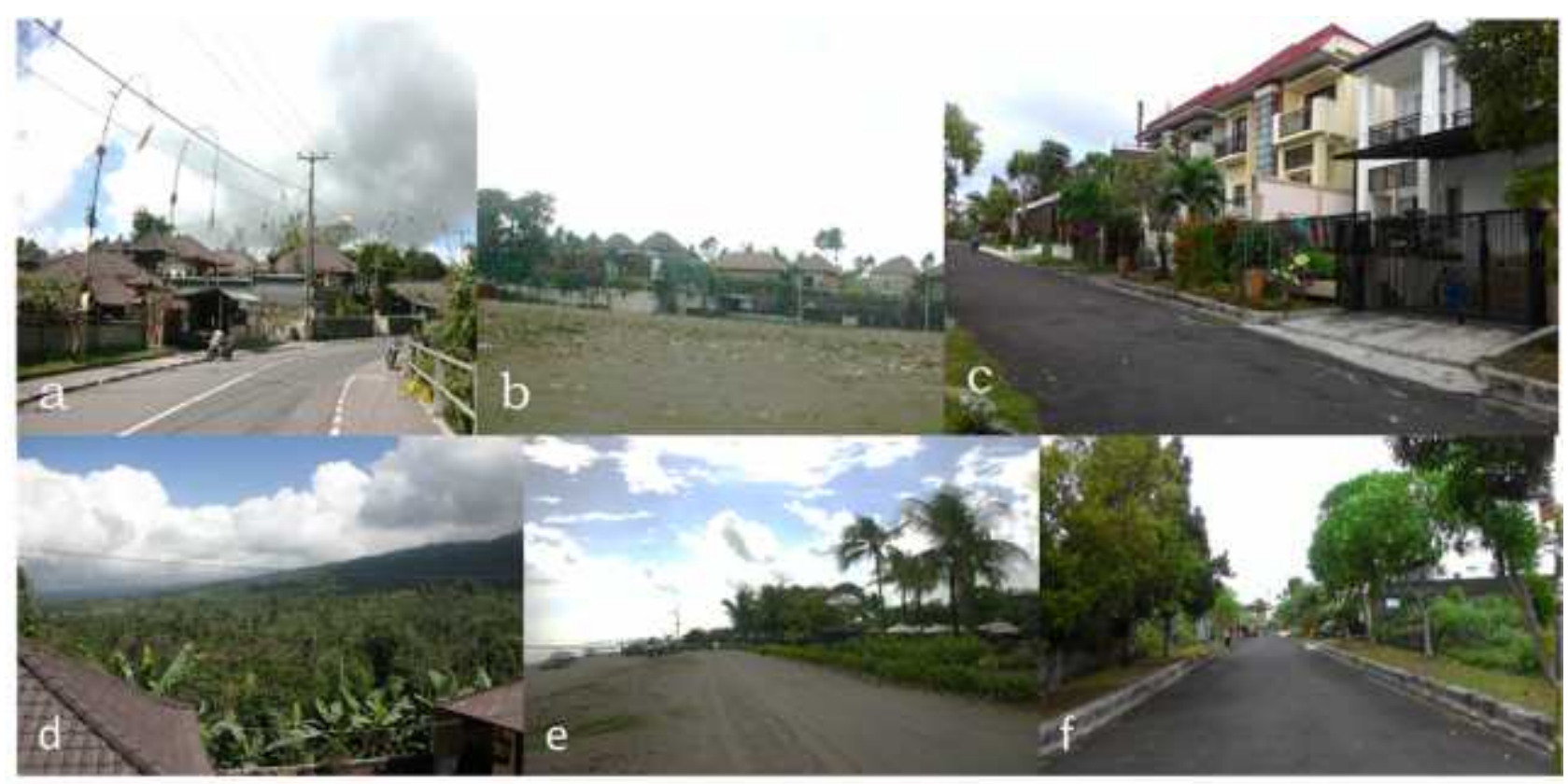

Gambar 4. Permukiman dan hijauan di sepanjang jalan Badung Utara (a,d); Tengah (b,e); Selatan (c,f).

Kemiringan 3 (15-25\%)

Kepadatan permukiman cukup rendah, permukiman dibangun mengikuti kontur, daerah-daerah yang miring ditanami tanaman sela seperti kopi, umumnya hanya terdiri atas 1 baris perumahan yang linier mengikuti jalan (Gambar 5 a,d). Model bangunannya masih tradisional dan cenderung homogen. Pekarangan sudah mulai ditata walaupun sederhana. Ladang sebagai sumber penghasilan warga berada di samping rumah, sudah ada ruko walaupun masih sangat jarang. Permukiman masih dilatarbelakangi oleh pepohonan hijau. Bangunan belum tinggi, karakter pegunungan terasa. Ada akses masuk yang miring untuk manusia, maupun kendaraan bermotor di depan rumah. Permukiman di Badung Tengah tergolon padat, dengan rumah tipe minimalis, pekarangan hampir tidak ada, sehingga tanaman ditanam di telajakan rumah (Gambar 5b,e). Permukiman di Badung Selatan (Gambar 5c,f) pada kemiringan ini cukup sedikit, permukiman dibangun mengikuti kontur, daerah-daerah yang cukup curam dibiarkan berupa semak-semak liar. Model bangunannya semi modern hingga modern. Pekarangan sudah tertata. Permukiman masih dilatarbelakangi oleh semak sehingga karakter perbukitan kuat terasa. Akses masuk dapat privat maupun umum. 


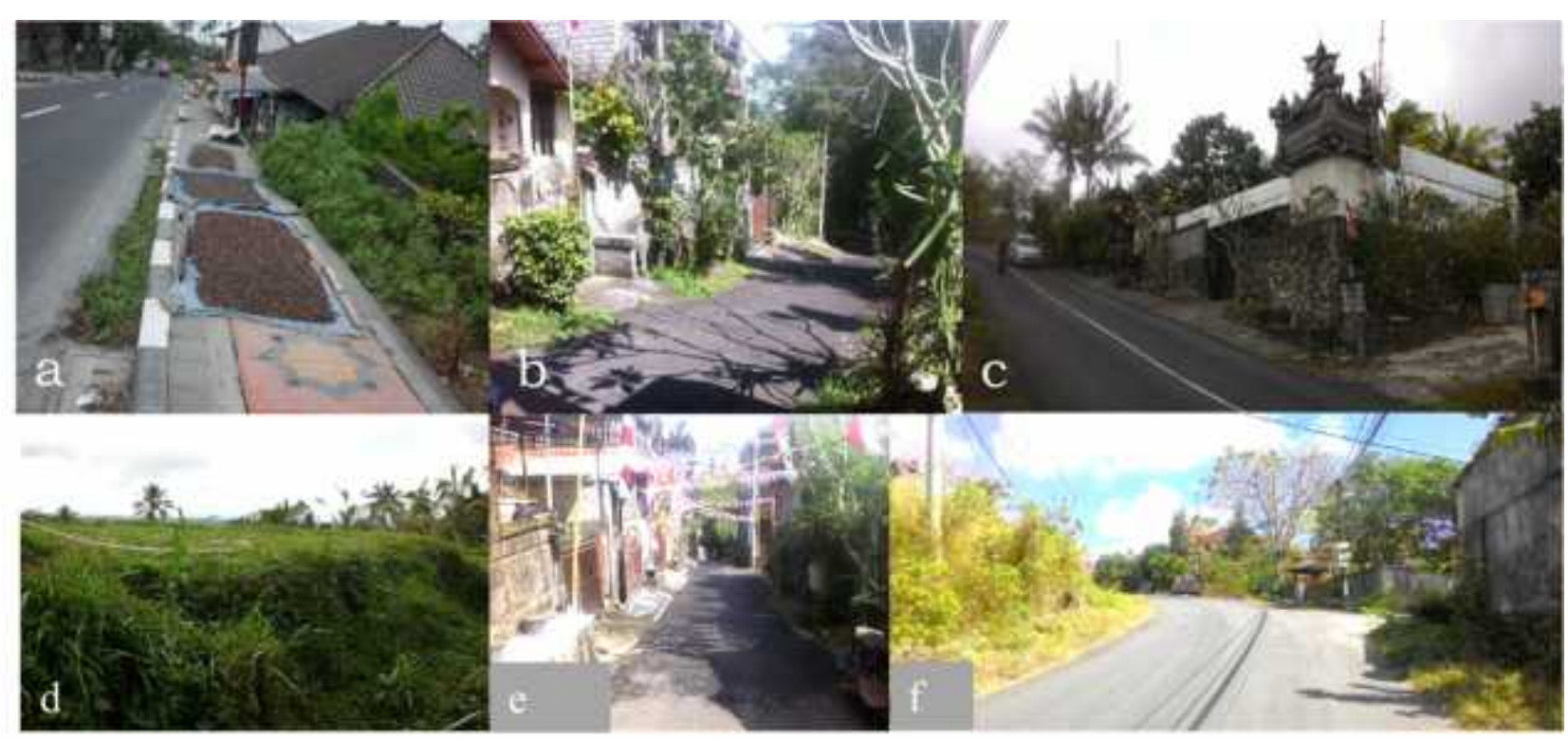

Gambar 5. Permukiman dan hijauan di sepanjang jalan Badung Utara (a,d); Tengah (b,e); Selatan (c,f).

Kemiringan 4 (25-45\%)

Kepadatan permukiman di Badung Utara tergolong rendah, permukiman dibangun mengikuti kontur, daerah-daerah yang miring ditanami tanaman sela seperti kopi, umumnya hanya terdiri atas 1 baris perumahan yang linier mengikuti jalan (Gambar 6a.). Model bangunannya masih tradisional dan cenderung homogen. Pekarangan sudah mulai ditata walaupun sederhana. Ladang sebagai sumber penghasilan warga berada di samping rumah. Permukiman masih dilatarbelakangi oleh pepohonan hijau. Bangunan belum tinggi, suasana pegunungan terasa. Badung tengah belum terdapat permukiman di kemiringan ini. Sementara Badung Selatan, permukiman terdiri atas rumah, hotel mapun vila yang terpisah cukup jauh antar bangunan satu dengan yang lainnya. Permukiman dibangun mengikuti kontur, daerah-daerah yang cukup curam dibiarkan berupa semak-semak liar (Gambar 6b.). Model bangunannya cenderung modern. Pekarangan sudah tertata. Permukiman masih dilatarbelakangi oleh semak sehingga suasana perbukitan kuat terasa. Akses masuk dapat privat maupun umum.

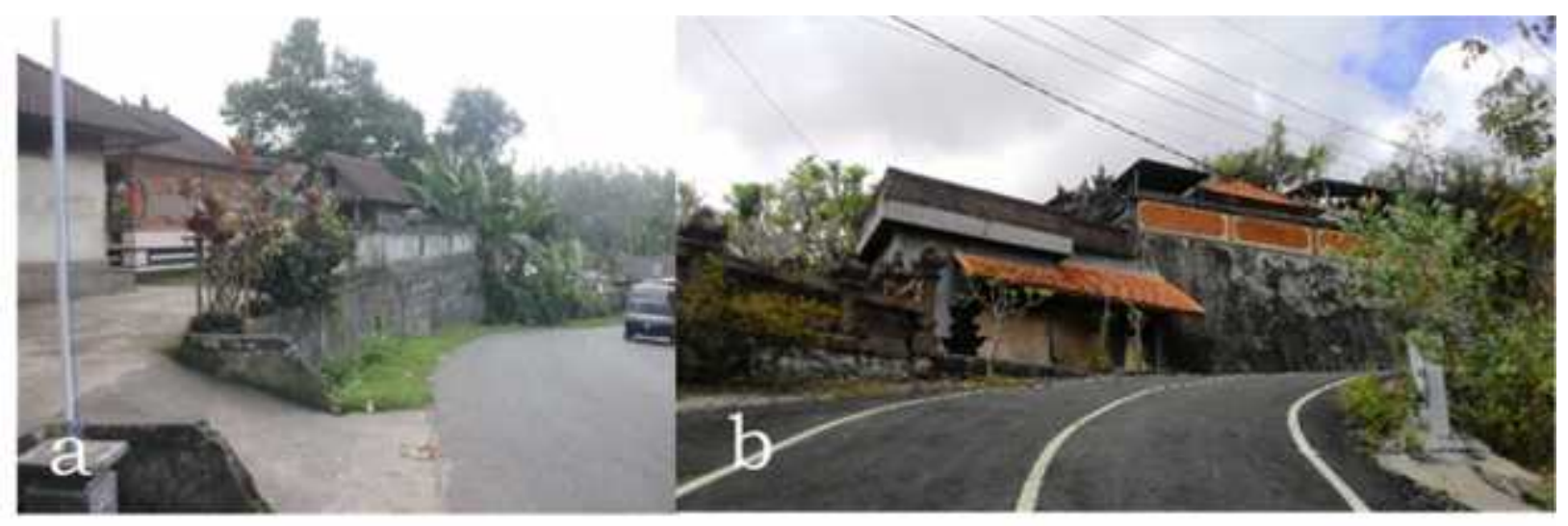

Gambar 6. Permukiman dan hijauan di sepanjang jalan Badung Utara (a); dan Selatan (b). 
Kemiringan 5 (>45\%)

Pada penelitian ini, belum ditemukan permukiman pada kemiringan 5 di Badung Utara maupun tengah, area terbangun pada Badung Utara berupa Pura maupun area terbangun yang tidak memiliki akses umum untuk dilalui kendaraan (Gambar 7a.). Area terbangun berada di tengah hijauan dan cukup sulit dijangkau. Permukiman di kemiringan sangat curam pada Badung Selatan didominasi oleh hotel maupun villa eksklusif (Gambar 7b.). Bangunan dan penataan sudah sangat terencana. Akses mudah namun tertuju khusus untuk ke bangunan tersebut.

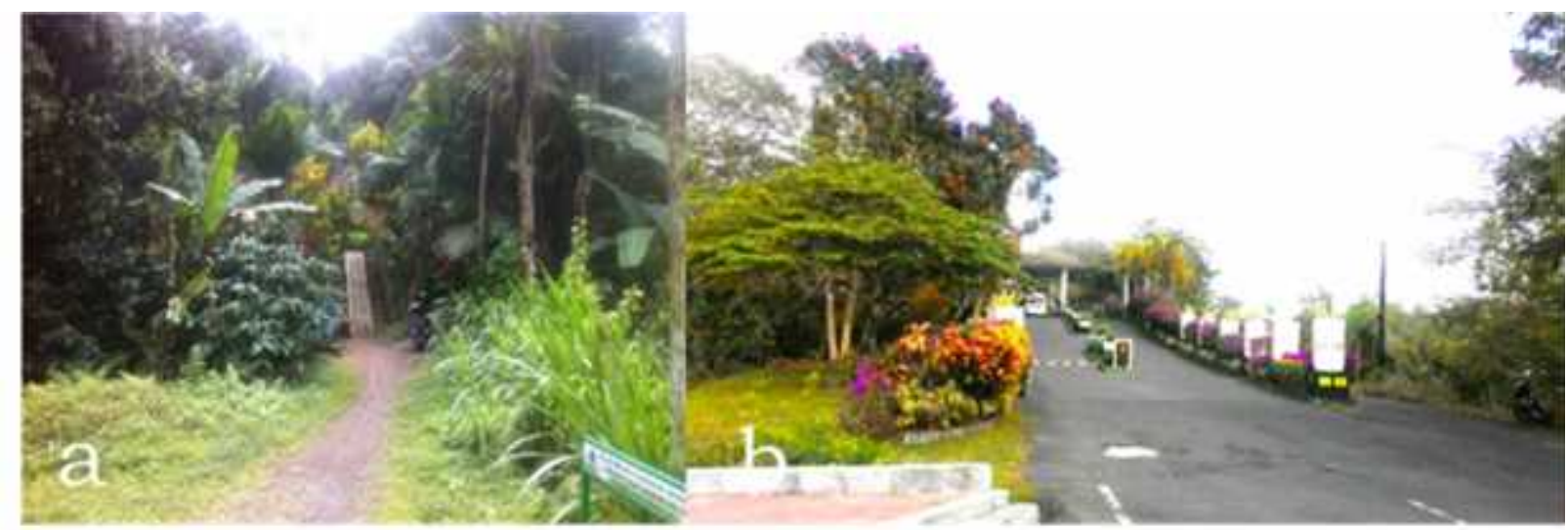

Gambar 7. Permukiman di sepanjang jalan Badung Utara (a); dan Selatan (b).

\section{KESIMPULAN}

Kecamatan yang didominasi oleh lereng 1 dan 2 seperti Kuta Utara dan Kuta telah mengembangkan area sekitar 98\%. Kuta Selatan memiliki area permukiman hingga lereng 4 dan area lainnya yang dikembangkan seperti hotel dan villa hingga lereng 5. Petang, didominasi oleh daerah dengan lereng 3-5 memiliki area yang dikembangkan sekitar $20 \%$ di mana area permukiman berada di lereng 1-4. Perbedaan karakter permukiman antar wilayah pembangunan terutama disebabkan oleh perbedaan sosial ekonomi masyarakatnya.

\section{SARAN}

Perlu dilakukan penelitian lebih lanjut mengenai peran dan motivasi penduduk dalam membangun rumah, serta menata permukimannya.

\section{UCAPAN TERIMA KASIH}

Terima kasih penulis ucapkan kepada LPPM Unud yang telah membiayai sepenuhnya penelitian ini melaui DIPA PNBP Universitas Udayana TA-2018 Sesuai dengan Surat Perjanjian Penugasan Pelaksanaan Penelitian Nomor: 985/UN14.2.6.II/LT/2018. Terima kasih kepada seluruh pihak yang telah membatu terlaksananya penelitian ini

\section{DAFTAR PUSTAKA}

[BPS] Badan Pusat Statistik. 2017. Kabupaten Badung dalam Angka 2017. BPS Kabupaten Badung, Bali. ISSN:0215-5257. 
[BPS] Badan Pusat Statistik. 2018. Proyeksi Penduduk Provinsi Bali Menurut Jenis Kelamin dan Kabupaten/Kota, 2011-2020 (ribu jiwa). Tersedia pada: https://bali.bps.go.id/linkTableDinamis/view/id/115. (diakses 31 Januari 2018).

[Pemkab Badung] Pemerintah Kabupaten Badung. 2018. Sektor Unggulan. https://badungkab.go.id/page/read/30. (diakses 31 Januari 2018).

Antrop M. 2004. Landscape change and the urbanization process in Europe. Landscape and Urban Planning 67:9-26. doi:10.1016/S0169-2046(03)000264.

Black AE, Morgan P, Hessburg PF. 2003. Social and biophysical correlates of change in forest landscapes of the interior Columbia Basin, USA. Ecological Applications 13(1):51-67.

[CLCA] Current Landscape Character Assessment. 2003. Northamptonshire Current Landscape Character Assessment. http://www.rnrpenvironmental character.org.uk/data/4.1\%20CLCA.pdf. (diakses 31 Januari 2018)

Du X, Jin X, Yang X, Yang X, Zhou Y. 2014. Spatial pattern of land use change and its driving force in jiangsu province. Int. J. Environ. Res. Public Health (11):3215-3232. doi:10.3390/ijerph110303215.

Elmhagen B, Kindberg J, Hellstrom P, Angerbjorn A. 2015. A boreal invasion in response to climate change? Range shifts and community effects in the borderland between forest and tundra. AMBIO 44(1):39-50. doi: 10.1007/s13280-014-0606-8.

Hudayya, R. 2010. Aplikasi Sistem Informasi Geografis untuk Analisis Pola Sebaran dan Perkembangan Permukiman (Studi Kasus Kabupaten Bogor, Jawa Barat). Skripsi. Program Studi Manajemen Sumberdaya Lahan Departemen Ilmu Tanah dan Sumberdaya Lahan, Institut Pertanian Bogor, Bogor.

Marwasta D, Priyono KD. 2007. Analisis Karakteristik Permukiman Desa-Desa Pesisir di Kabupaten Kulonprogo. Forum Geografi 21(1):57-68.

Odeh T, Boulad N, Abed O, Yahya AA, Khries N, Jaber N. 2017. The Influence of Geology on Landscape Typology in Jordan: Theoretical Understanding and Planning Implications. Land 6(51).

Peng LP, Hsieh YS. 2015. Settlement Typology and Community Participation in Participatory Landscape Ecology of Residents. Landscape Research. http:/ / dx.doi.org/10.1080/01426397.2014.967190.

Putri YY. 2013. Kajian Lanskap Permukiman Tradisional Masyarakat Lampung Saibatin di Pekon Kenali, Lampung Barat. Tesis. Sekolah Pascasarjana, Institut Pertanian Bogor, Bogor.

Sarwar MI, Billa M, Paul A. 2016. Urban land use change analysis using RS and GIS in Sulakbahar ward in Chittagong city, Bangladesh. International Journal of Geomatics and Geosciences 7(1):1-10. 
Wu J, Jenerette GD, David JL. 2003. Linking Land-Use Change with Ecosystem Processes: A Hierarchical Patch Dynamic Model. In Guhathakurta S (ed). Integrated Land Use and Environmental Models. Springer, Berlin:99-119.

Xie Y, Yu M, Bai Y, Xing X. 2006. Ecological analysis of an emerging urban landscape pattern-desakota: a case study in Suzhou, China. Landscape Ecol 21:12971309. doi: $10.1007 / \mathrm{s} 10980-006-0024-9$. 